\title{
Seismic evidence for ultralow-velocity zones beneath Africa and eastern Atlantic
}

\author{
Don Helmberger, Sidao Ni, Lianxing Wen, ${ }^{1}$ and Jeroen Ritsema \\ Seismological Laboratory, California Institute of Technology, Pasadena
}

\begin{abstract}
S K S$ waveforms recorded at distances of about $110^{\circ}$ are extremely useful to constrain seismic velocity structure at the base of the mantle. $S K S$ waves near this distance develop a complicated interference pattern with the phases $S P_{d} K S$ and $S K P_{d} S$. We report anomalous behavior of this interference in a number of recordings of deep earthquakes beneath South America from stations in Europe and Africa. We model these data with two-dimensional dome-like structures at the base of the mantle which extend laterally by a few hundred kilometers and in which the shear velocity is up to $30 \%$ lower than in the Preliminary Reference Earth Model (PREM). The spatial extent of these structures, their position with respect to the $S K S$ core exit points, and their seismic characteristics can not be uniquely determined. However, the presence of a dipping or a concaved upper interface is a key attribute of successful models. Models that invoke flat layers are insufficiently complex to explain the most erratic waveform behavior. The most anomalous data correspond to sampling regions at the base of the mantle beneath the East African Rift and beneath the Iceland, where possibly, whole mantle upwellings form.
\end{abstract}

\section{Introduction}

The lowermost $300 \mathrm{~km}$ of the mantle (termed D" in this paper) is a complex region according to seismological observations and geodynamic models. It contains a thermal boundary layer at its base which transmits about 10 to $15 \%$ of the Earth's heat flow [Davies, 1980]; it is highly heterogeneous, and it may well influence convection in the core and mantle [Lay et al., 1998].

Seismic models of D" are derived using a variety of data. Tomographic maps of D" [e.g., Li and Romanowicz, 1996; Masters et al., 1996; Grand et al., 1997; Ritzwoller and Lavely, 1995] are primarily based on body wave travel times. They show regions with relatively high seismic velocity (compared to Preliminary Reference Earth Model (PREM) [Dziewonski and Anderson, 1981]) beneath the circum-Pacific which possibly represent the seismic signatures of downwelling slabs [e.g., Engebretson et al., 1992]. Broad low seismic velocity anomalies, which may represent large-scale upwellings, are present beneath Africa and the central Pacific where subduction has not occurred since the Mesozoic [e.g., Chase and Shrowl, 1983]. These low-velocity regions contain many of the world's hot spots [Crough and Jurdy, 1980], and they correlate with the long-wavelength geoid highs as expected for a convecting mantle [Hager et al., 1985]. Additional seismological constraints on the spatial extent, seismic velocity gradients, and shear velocity anisotropy within these large-scale anomalies have come from the modeling of $P c P$ precursors [Mori and Helmberger, 1995; Revenaugh and Meyer, 1997], broadband $S K S$ and $S P_{d} K S$ waveforms [Garnero and Helmberger, 1996], differential travel times [Breger and Romanowicz, 1998], broadband precursors to PKP [Wen and Helm-

\footnotetext{
${ }^{1}$ Now at Department of Terrestrial Magnetism, Carnegie Institution of Washington, Washington, D.C.
}

Copyright 2000 by the American Geophysical Union.

Paper number $2000 \mathrm{JB} 900143$. 0148-0227/00/2000JB900143\$09.00 berger, 1998a], and SV-SH polarization [Lay et al., 1998]. Most of these body wave modeling efforts focused primarily on the Pacific anomaly which is well sampled by seismic waves that propagate from deep earthquakes in the western $\mathrm{Pa}$ cific to stations in North America.

Recently, high-quality broadband data have been provided by the 1994-1995 experiment in Tanzania [Nyblade et al., 1996; Ritsema et al., 1998a], which enables us to study the deep mantle beneath Africa by waveform modeling. In particular, recordings of earthquakes in the southwestern Atlantic Ocean at the Tanzania array show large shear wave travel time delays that indicate the presence of anomalous structure in the lower mantle beneath Africa (Plate 1).

Plate 1a shows $S$ and $S c S$ travel time delays (with respect to PREM) of an event in the Sandwich Islands, while Plate $1 \mathrm{~b}$ shows $S$ and $S K S$ delays by an event in the Drake Passage. The $S, S c S$, and $S K S$ waves propagate through the same mantle corridor between the Drake Passage and central Asia (Plate 2). Note that the delay of $S$, generated by the Sandwich Island event, increases systematically from about zero at $65^{\circ}$ to about $10 \mathrm{~s}$ at $75^{\circ}$. ScS phases are delayed by about $12 \mathrm{~s}$ over the entire distance range. The Tanzania array was installed on the boundary between the Tanzania Craton and the East African Rift. Ritsema et al. [1998b] estimate that about 3-4 s of the $S$ delay is caused by anomalously low seismic velocity structure beneath the rift. The most compelling evidence that the remaining 6-8 $\mathrm{s}$ of the delay of $S$ and $S c S$ is caused by low- velocity structure in the lower mantle beneath Africa is provided by the $S K S$ data from the Drake Passage event shown in Plate 1b. The trend of $S K S$ delays is opposite from the trend of $S$ and $S c S$ of the Sandwich Island earthquake even though the paths through the upper mantle are virtually identical.

These data have been modeled by Ritsema et al. [1998b] with a continuous two-dimensional (2-D) structure that extends $1500 \mathrm{~km}$ into the mantle and which contains a uniform $3 \%$ drop in shear velocity relative to PREM. The model displayed in Plate 1, however, was obtained by adopting the tomographic model of Grand [1994] in which the shear velocity anomalies in the midmantle (1500-2600 km depth) have been 


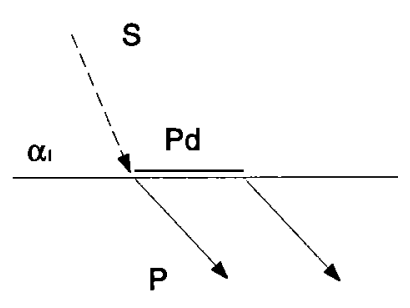

SPdKS

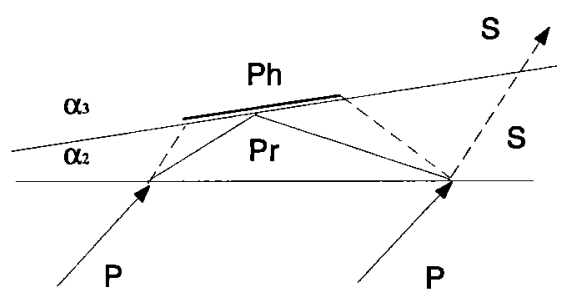

SKPdS

Figure 1. Schematic ray plots displaying direct $S$ entering the core as $P$ along with a diffracted ray $P_{d}$ on the left and $P$ exiting the core as $S$ and containing a $P$ multiple in a slow layer on the right. The response can reach critical angle if $\alpha_{3}>\alpha_{2}$ as indicated which can enhance or reduce amplitudes by locally dipping. We will refer to these two packets of rays as (a) $S P_{d} K S$ and (b) $S K P_{d} S$.

enhanced [Ni et al., 2000]. This model explains the data of Plate 1 as well as $S-S K S$ differential travel times from South American events recorded in Africa. We introduce this model to define the shear velocity anomaly above the D" region as the African low-velocity zone (ALVZ), but we do not imply that the ALVZ is necessarily detached from the D", although it is in Grand's [1994] tomographic results. Dynamic models can reproduce ALVZ-type structures by invoking strong depth-dependent viscosity [Thompson and Tackley, 1998; Zhang and Yuen, 1997]. However, broad upwellings tend to efficiently remove the core-mantle boundary (CMB) thermal boundary layer, leading us to question what this slow D" structure beneath the ALVZ is, whether it contains ultralowvelocity zones (ULVZ) at its base, and how it relates to whole mantle upwellings in general.

\section{Analysis}

The seismic phases $S P_{d} K S$ and $S K P_{d} S$ are most clearly observed in radial component seismograms recorded at epicentral distances larger than $105^{\circ}-110^{\circ}$. These phases arrive just behind the seismic phase $S K S$ and are produced when $S$ impinges upon the $\mathrm{CMB}$ at the critical $S$-to- $P$ conversion angle [Kind and Müller, 1975]. The paths of $S K S, S P_{d} K S$, and $S K P_{d} S$ are very similar in the core and mantle. However, $S P_{d} K S$ and $S K P_{d} S$ also contains short $\mathrm{P}$ diffractions along the base of the mantle (Figure 1). By analyzing the interference of $S P_{d} K S$ and

Table 1. South American Events List

\begin{tabular}{llllll}
\hline \multirow{2}{*}{ No. } & \multicolumn{2}{c}{ Origin } & $\begin{array}{l}\text { Lat } \\
\text { (deg) }\end{array}$ & $\begin{array}{l}\text { Long } \\
(\mathrm{deg})\end{array}$ & $\begin{array}{l}\text { Depth, } \\
\text { km }\end{array}$ \\
\cline { 2 - 6 } 1 & Dept. 17.1965 & $1113: 53.5$ & -14 & -77.7 & 161 \\
2 & Nov.3, 1965 & $0139: 3.20$ & -9.04 & -71.32 & 587 \\
3 & Feb. 15 1967 & $1611: 11.5$ & -907. & -71.38 & 595 \\
4 & Sept.9,1967 & $106: 44.5$ & -2762 & -63.15 & 577 \\
5 & Dec. 27,1967 & $0853: 51.4$ & -21.2 & -68.3 & 135 \\
6 & Aug. 23,1968 & $2236: 49.8$ & -22 & -63.64 & 513 \\
7 & July 25,1969 & $066: 42.1$ & -25.49 & -63.21 & 573 \\
8 & June 4,1970 & $049: 25$ & -9.9 & -789 & 57 \\
9 & June 17,1970 & $0444: 20.9$ & -16 & -71.88 & 99 \\
10 & Feb. 21,1971 & $1035: 19.7$ & -23.8 & -67.19 & 165 \\
11 & May 8, 1971 & $0049: 45.0$ & -42.28 & -71.78 & 146 \\
12 & Oct. 25, 1973 & $148: 58.5$ & -21.96 & -63.65 & 517 \\
13 & Dec. 5,1974 & $1157: 31.1$ & -7.65 & -74.45 & 156 \\
14 & May 21,1979 & $2222: 23.0$ & -15.44 & -70.04 & 209 \\
15 & Sept. 15,1982 & $2022: 57.8$ & -14.53 & -70.79 & 153 \\
16 & Nov. 18,1982 & $1457: 51.3$ & -1.73 & -76.72 & 190 \\
17 & Dec. 12,1983 & $1221: 12.0$ & -28.13 & -63.15 & 602 \\
\hline
\end{tabular}

$S K P_{d} S$ with the $S K S$, we can constrain the fine-scale seismic velocity and density structure at the base of the mantle with relatively high resolution.

The PREM model predicts that $S P_{d} K S$ and $S K P_{d} S$ separate from $S K S$ near $110^{\circ}$. The bifurcation of $S K S$ can be seen in PREM synthetics shown on the right in Figure 2 as $S P_{d} K S$ and $S K P_{d} S$ form a single pulse (both phases have identical travel time) that is well separated from $S K S$ beyond about $114^{\circ}$. If the $P$ velocity at the base of the mantle is lower than in PREM, the bifurcation shifts to shorter distances [Garnero et al., 1993]. Thus identifying this bifurcation point becomes an excellent tool for constraining the $P$ velocity structure at localized regions just above the $\mathrm{CMB}$, although still ambiguous with respect to $S K S$ entry and exit points.

\subsection{Anomalous Waveform Data Sampling the Base of the Mantle Beneath Iceland and Africa}

The study of $S P_{d} K S$ and $S K P_{d} S$ waveforms requires recordings of relatively deep earthquakes in order to avoid interference with the surface reflections of $p S K S$ and $s S K S$. We selected World-Wide Seismograph Stations Network (WWSSN) recordings of 16 deep focus earthquakes (Table 1) beneath
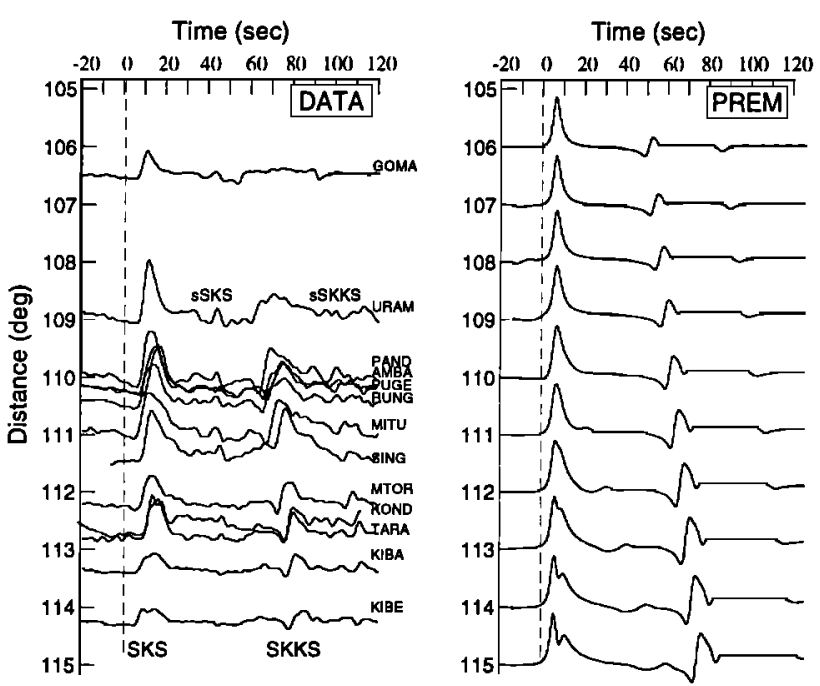

Figure 2. Display of Tanzania array waveform data (radial displacement) containing $S K S$ interference and corresponding synthetics generated with a reflectivity code. The event and path locations are given in Plate 2. 

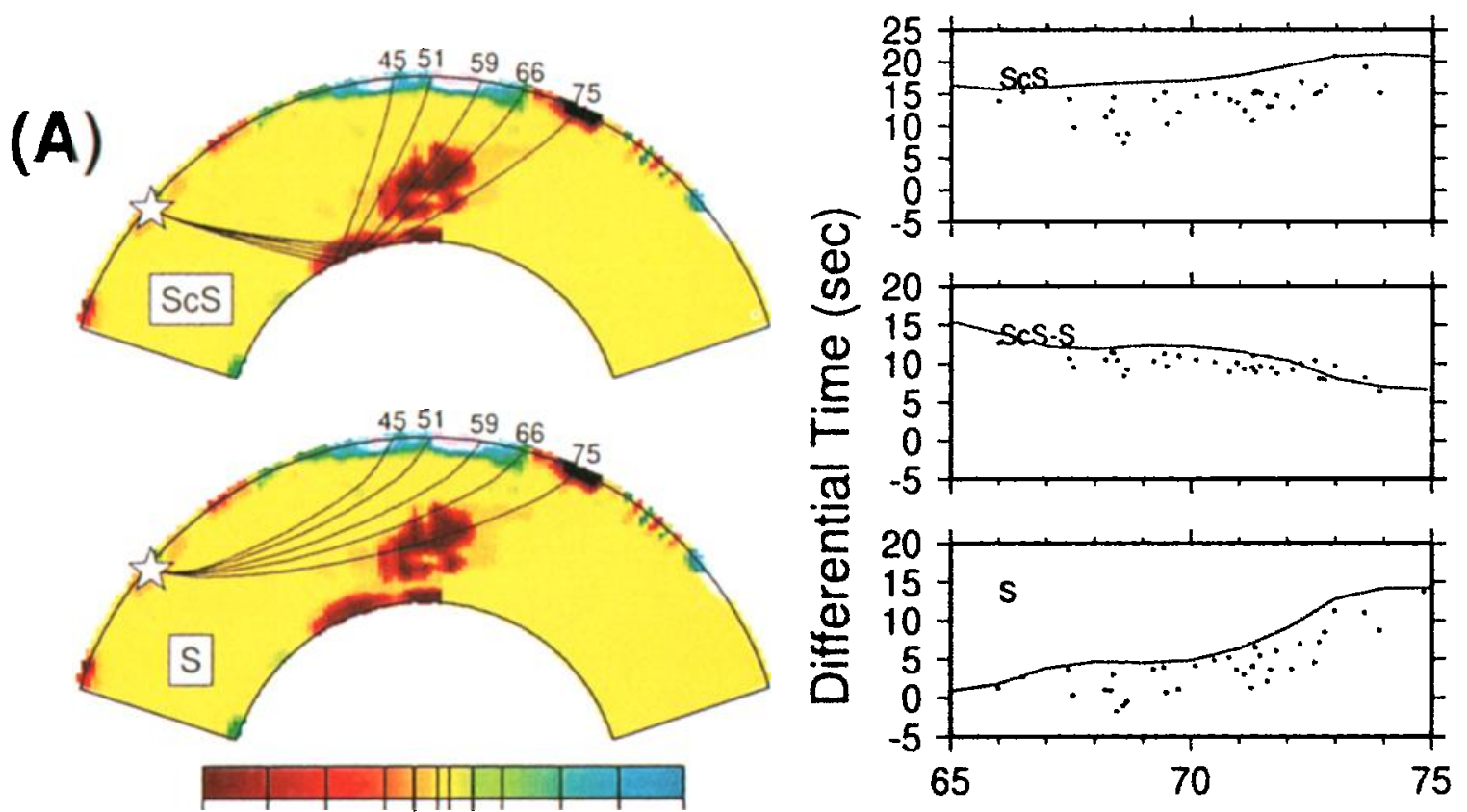

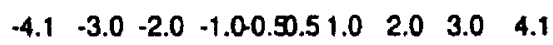
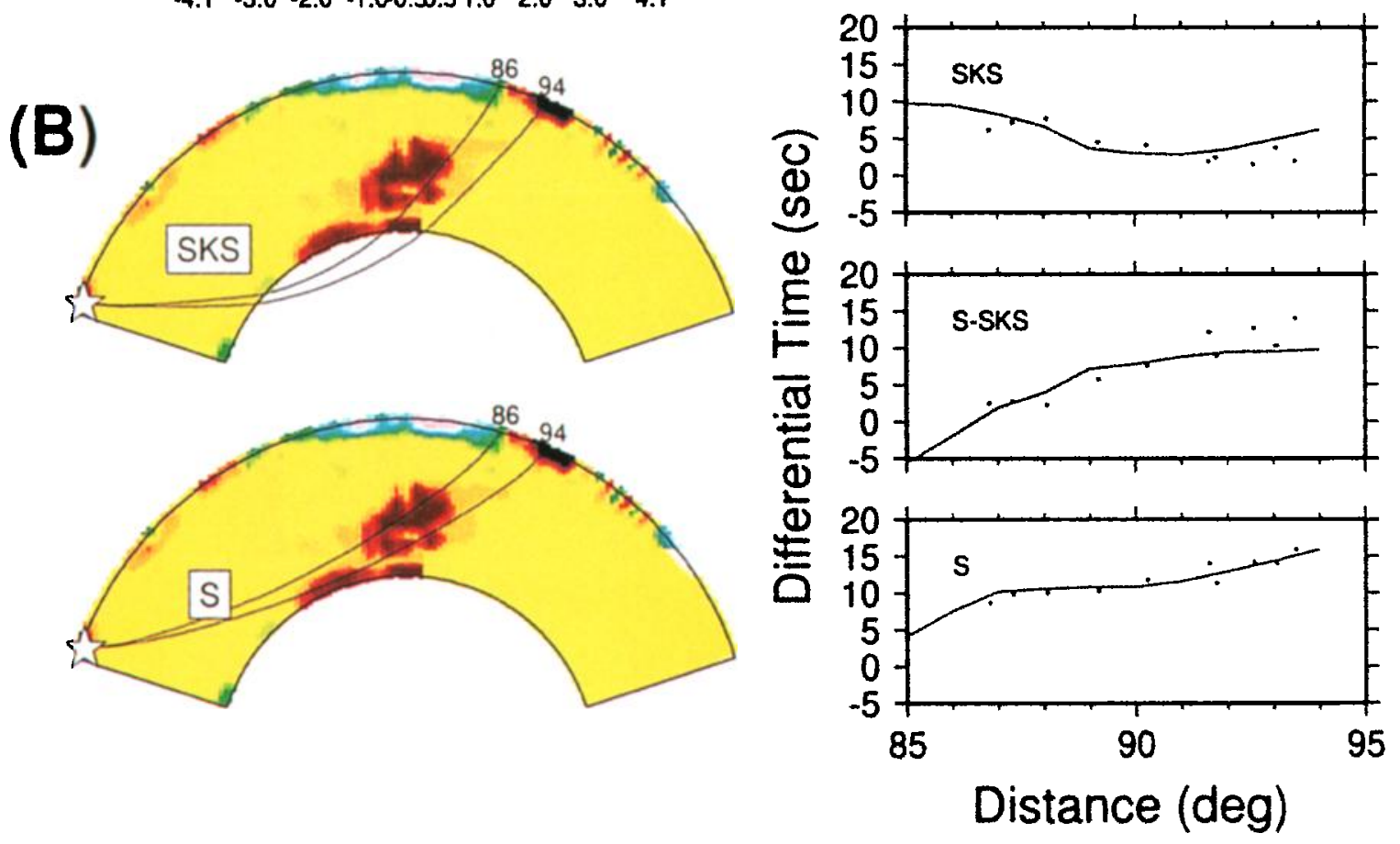

Plate 1. Cross sections of velocity structure connecting Sandwich Island to the Tanzania array (shaded lines in Plate 2) along with ray paths appropriate for (a) $S_{c} S$ and $S$ and (b) $S K S$ and $S$. The corresponding travel times on the right were computed from synthetics generated for these 2-D sections (solid lines) along with observed picks from the array as discussed by Ritsema et al. [1998b] reduced by PREM. The velocity model was derived from the tomographic images of Grand [1994] by applying an ad hoc enhancement scheme proposed by $\mathrm{Ni}$ et al. [2000] for other profiles. 


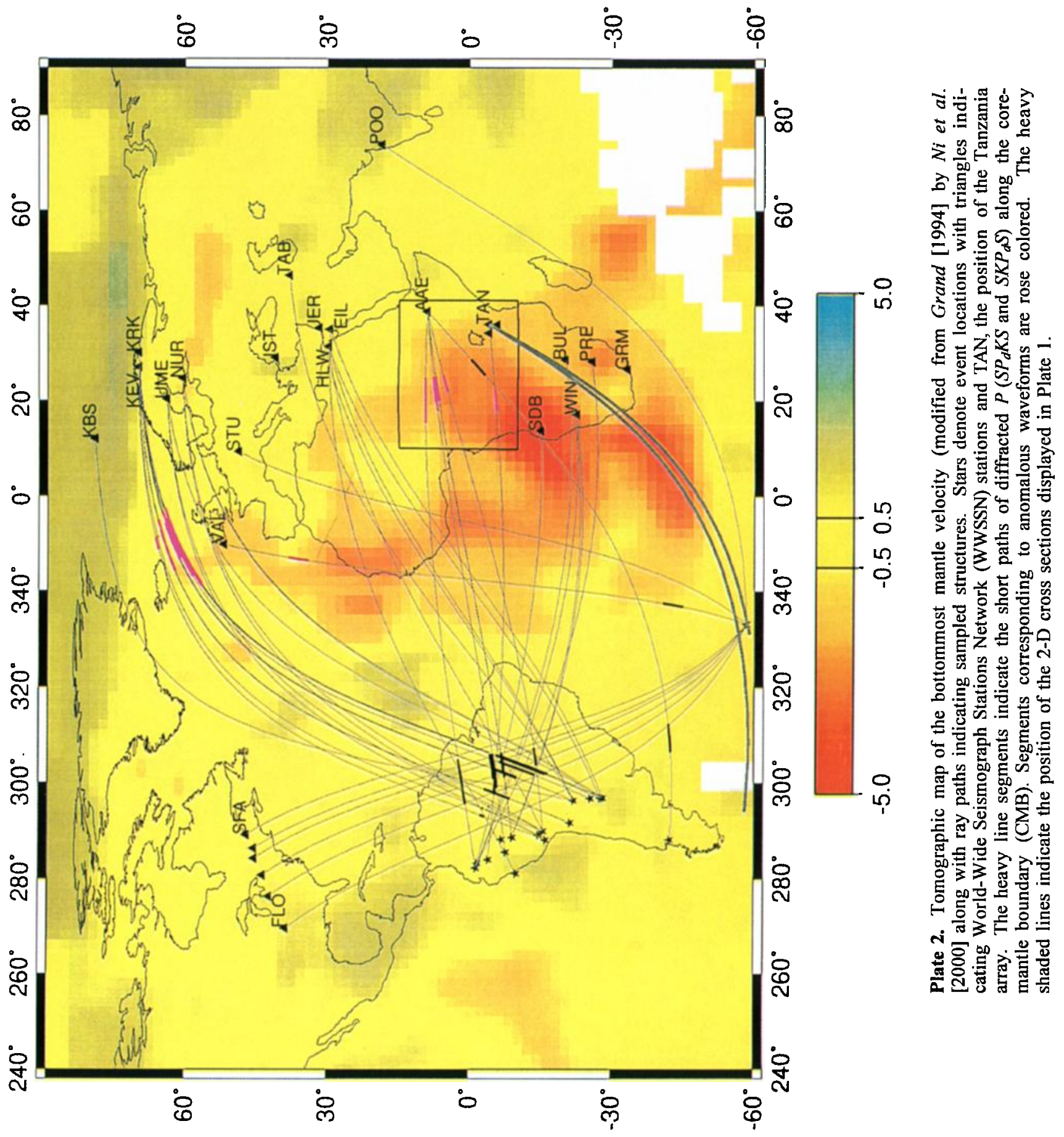


South America and Tanzania array recordings for an earthquake beneath Colombia. The Colombia event was at a depth of 70 $\mathrm{km}$ and the phase $s S K S$ arrives well after $S K S$ and $S K K S$ (Figure 2). The waveform data shown in Figure 2 are anomalous in several aspects. First, the travel time of $S K S$ is delayed by about 5-10 s. The $S K S$ delay is particularly large at stations AMBA and PUGE, apparently owing to the local rift structure [Ritsema et al., 1998a]. Second, there is an abrupt change in the amplitude ratio of $S K K S$ to $S K S$ beginning at about $110^{\circ}$ with a noticeable increase indicative of the interference caused by the $S K S$ bifurcation. Third, several $S K S$ pulses are anomalously broader than predicted by PREM, especially at stations
MITU and SING. At larger distances, $S K S$ and $S K P_{d} S$ are obvious as two distinct pulses in the data. The differential travel time of $S K S$ and $S K P_{d} S$ is well predicted by PREM synthetics, but the amplitude of $S K P_{d} S$ is anomalously large.

A sample of radial component WWSSN recordings is given in Figure 3 along with PREM synthetics in Figure 3a. These data are divided shown in Figures 3b-3d. Figure 3b (Normal) contains recordings that can, to a large extent, be explained by the PREM model. Recordings for distances smaller than $110^{\circ}$ (UME 9 at $104^{\circ}$ through UME 7 at $110^{\circ}$ ) show simple $S K S$ pulses similar to the PREM synthetics. $S K S$ and $S K P_{d} S$ emerge as separate signals in the record EIL at 9 near $111^{\circ}$, as pre-

\section{$\begin{array}{llll}\text { (a)PREM } & \text { (b)Normal } & \text { (c)lceland } & \text { (d)Africa }\end{array}$}

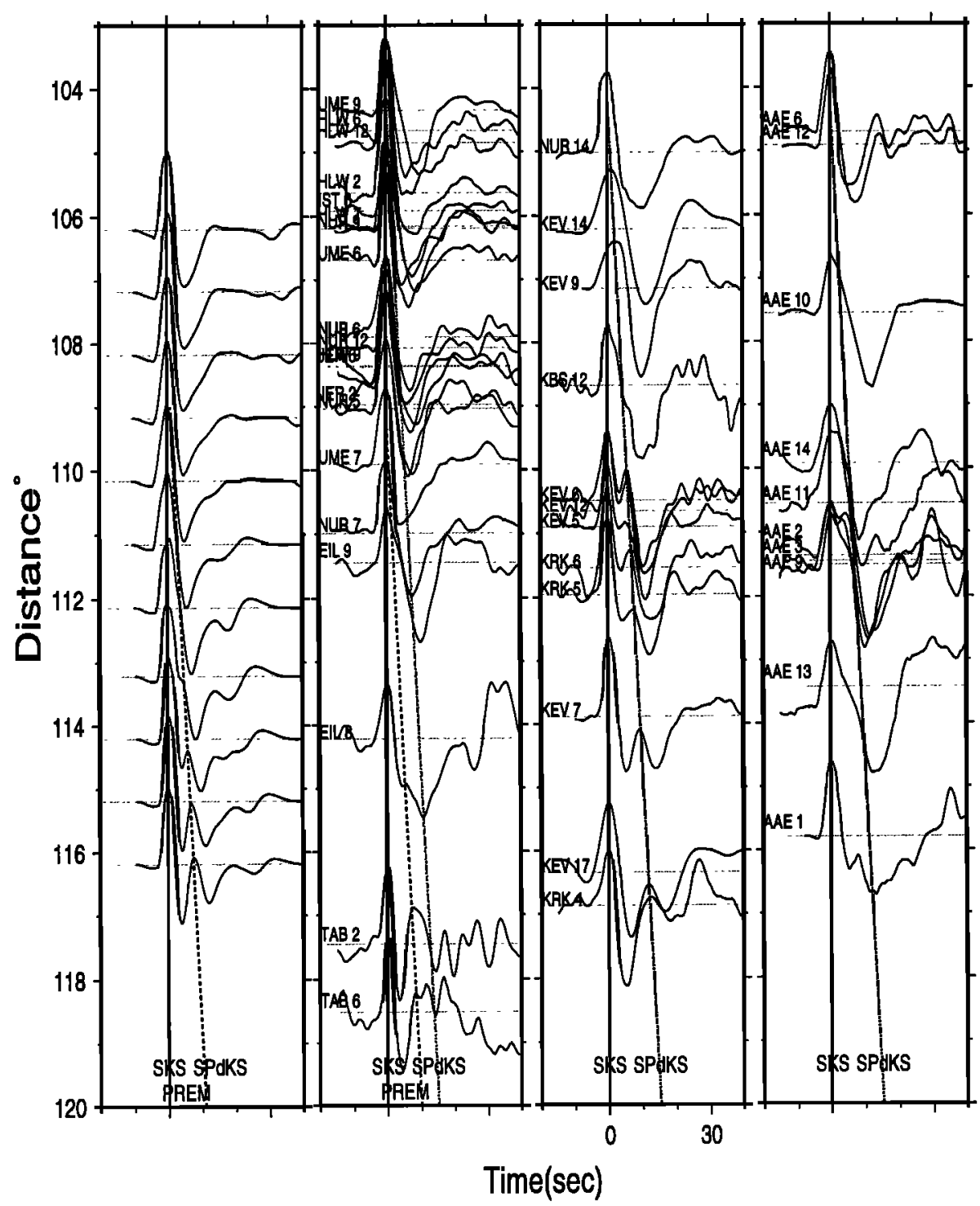

Figure 3. Display of (a) PREM synthetics accompanied by (b)-(d) analog WWSSN records (radial component) of $S K S$ and diffractions displaying normal and anomalous waveforms (beneath Iceland (Figure 3c) and Africa (Figure 3d)). The numbers indicate events as identified in Table 1. The stations are identified by their three latter codes with corresponding locations given in Plate 2. Timing lines appropriate for $S K S, S P_{d} K S$ (PREM), and $S K P_{d} S$ (anomalous with respect to Iceland data) are included. Note that events 5,6 , and 12 appear relatively simple at stations on the left while the recordings of these events at KEV and KRK are complex. The same feature occurs at AAE for events 2 and 9. Note also that the two traces of AAE that are not very anomalous, AAE11 and AAE1, correspond to the southern and northernmost paths. 
dicted by PREM. The $P$ diffractions associated with the normal data propagate primarily through regions of $D$ " where the average seismic wave velocity is PREM-like [Garnero and Helmberger, 1995, 1998]. The waveforms in Figure 3c (Iceland) yield strong secondary arrivals that develop at much shorter distances than in the normal recordings in Figure $3 \mathrm{~b}$. Compare, for example, the broad signals in recordings KEV 14 with the relatively narrow $S K S$ signals in recordings NUR 14 inserted above it for direct comparison. This same feature occurs in KEV 14 when compared with UME 9. This implies that the path to KEV is anomalous near the CMB, since this broadness does not appear to be a source effect. Figure 3d (Africa) shows anomalous recordings at station $\mathrm{AAE}$ in eastern Africa. We emphasize recordings AAE 2, AAE 3, and AAE 9. The "shoulder" on AAE 14 is similar to that of KBS. Note that these types of features occur in the PREM synthetics and more normal type data at great distances, i.e., EIL 9. However, the recording of event AAE 11 does not show this feature even though it is at the same distance. The path corresponding to AAE 11 is located farther to the south compared to the other recordings and could be a manifestation of lateral variation.

The great circle paths corresponding to the data of Figure 3 are shown in Plate 2. Heavy line segments represent the short $P$ wave diffracted path along the CMB boundary which are colored red if they are associated with anomalous waveform behavior. Note that the southern path segment associated with
AAE 11 is labeled black (normal) as compared to AAE 14, AAE 2, $\mathrm{AAE} 3$, and $\mathrm{AAE} 9$, which are labeled red (anomalous). Here we assume that $D$ " structures causing the waveform complexity are located at the core exit locations of $S K S$ within or at the northern edge of the large-scale low shear velocity anomaly beneath Africa.

\subsection{Modeling the SKS Waveform Bifurcation}

To some extent, the waveform complexities seen in Figure 3 can be produced with 1-D models which invoke reduced $P$ velocities at the base of the mantle. Such models are effective in producing the delays of $S P_{d} K S$ and $S K P_{d} S$ and enhancing their amplitudes with respect to $S K S$ [Garnero et al., 1993]. Synthetics for basal layers with thickness from 10 to $40 \mathrm{~km}$ and with $P$ and $S$ velocity reductions of 5\% match the data well. If the anomaly is confined to either the core entry or core exit point of $S K S$, we need to increase the velocity anomalies to 10\% [Helmberger et al., 1996a]. Such one-sided structures with thickness variations ranging from 5 to $40 \mathrm{~km}$ fit are particularly useful to explain many anomalous mid-Pacific data [Garnero and Helmberger, 1995]. A sample of these observations is displayed in Figure 4a. Note that a secondary phase $\left(S P_{d} K S\right)$ emerges at epicentral distances smaller than $110^{\circ}$, and several recordings yield high-amplitude secondary pulses (denoted by the solid dots) that cannot easily be ex- (a) Fiji(1)

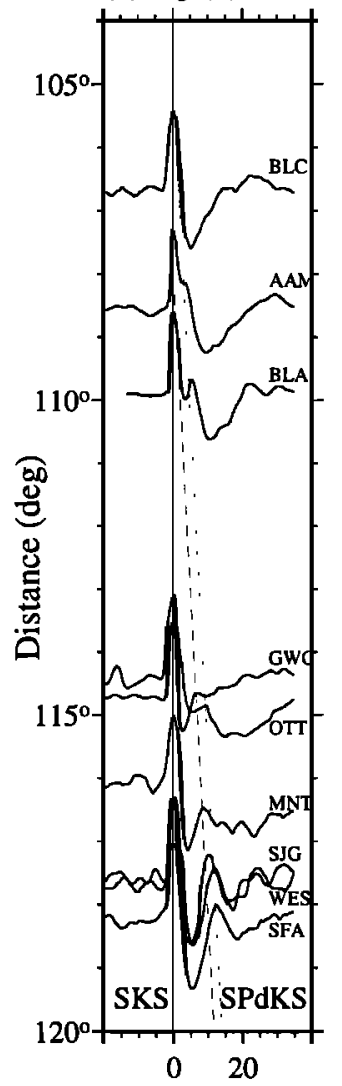

(b) Fiji(2)

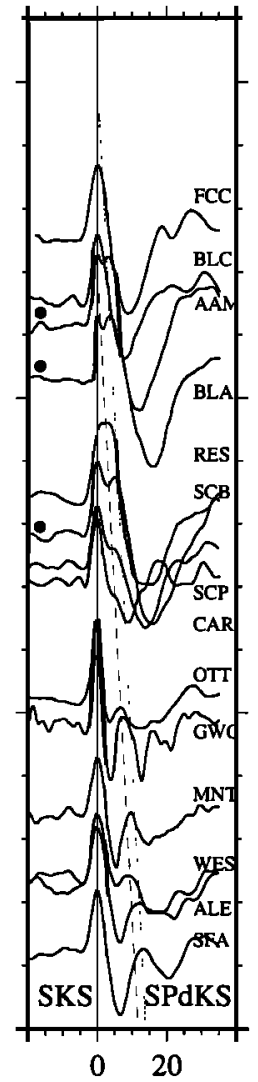

(c) Kermadec

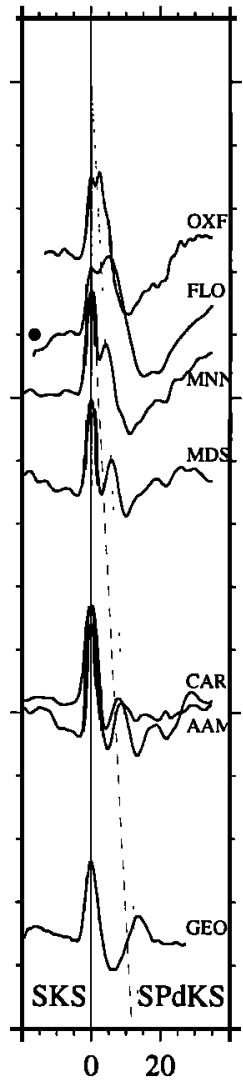

(d) Iceland

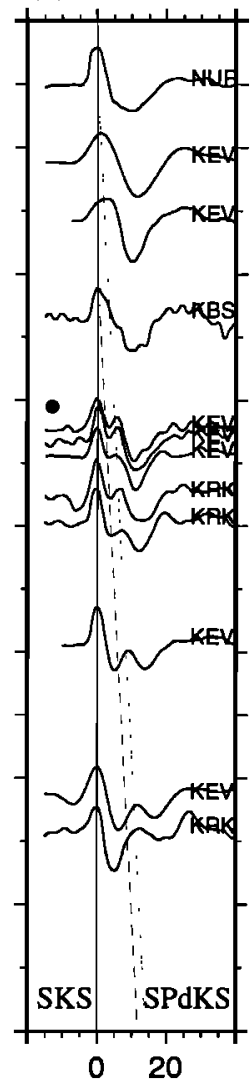

(e) Africa

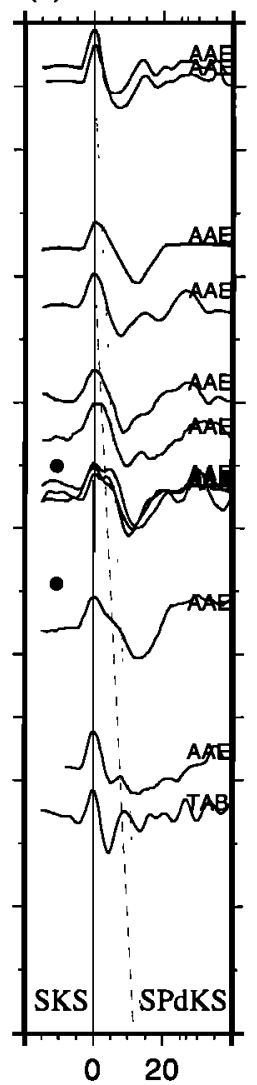

Time (sec)

Figure 4. Comparison of waveform observations from various anomalous regions. See Garnero and Helmberger [1998] for details about the Fiji and Kermadec events recorded in North America. The timing lines are the same in all columns indicating the $S K S$ arrival relative to observed diffracted $P$ (dotted) and theoretical PREM (dashed). 


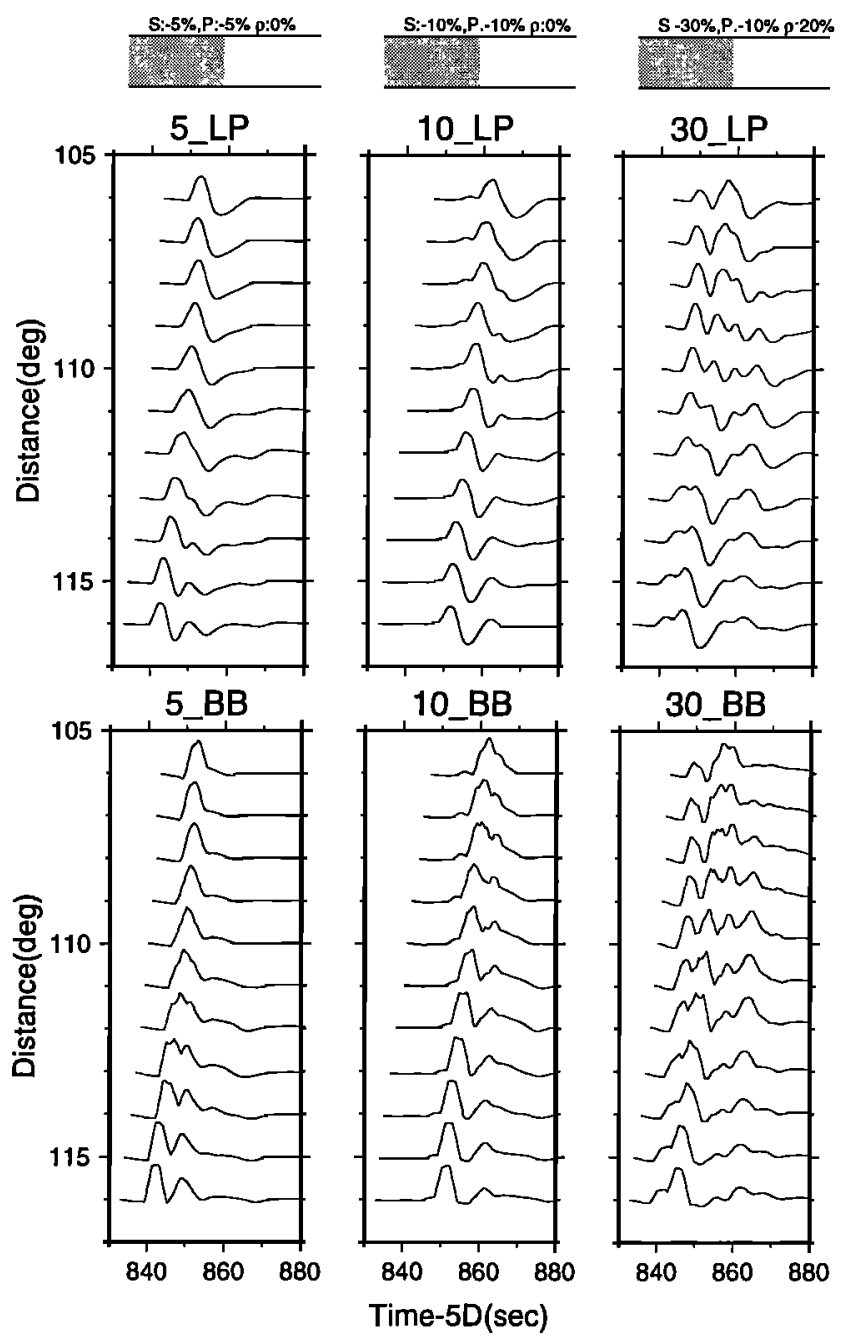

Figure 5. The three columns of synthetics are appropriate for three models assuming various degrees of drops in $P$ and $S$ velocity along with indicated at the top. The layer thickness is $30 \mathrm{~km}$. Mixed paths with a low-velocity layer for $S P_{d} K S$ and PREM for $S K P_{d} S$. (top) WWSSN (LP) simulation with (bottom) broadband $(\mathrm{BB})$ assuming a $(2,2,2)$ trapezoidal time history. These synthetics are plotted as a record section with a reducing velocity. Note the complexity as the shear velocity drops and shift of the interference to shorter distances.

plained with models that employ flat basal layers. Enhanced $S P_{d} K S$ and $S K P_{d} S$ amplitudes can be obtained when the shear velocity in basal layers is significantly reduced (Figure 5); however, an oscillatory wave train that follows SKS throughout the $110^{\circ}-110^{\circ}$ distance range has not been observed in the $S K S$ coda. By reducing the thickness of the basal layer the oscillatory wave train is suppressed [Garnero and Helmberger, 1998]. Nonetheless, strong SKS waveform distortions such as those shown in Figure 4 (dots) cannot be modeled with a simple flat-layered model since the observed second arrival is anomalously strong and develops early relative to PREM.

High-amplitude reflections are often recorded by stations located in sedimentary basins. These signals have been successfully modeled using dipping interfaces [Helmberger et al., 1983]. Models with dipping interfaces lend themselves also to the study of teleseismic $S K S$ waveform data. As illustrated in Figure 1, a structure dipping upward allows for the development of high-amplitude $S K P_{d} S$ signals at relatively short epi- central distances without introducing complex $S K S$ coda. Synthetics for models with dipping interfaces can be computed using 1-D model by simply increasing the velocity contrast locally, where $\alpha_{3}$ becomes the apparent velocity referred to as the "local stretching approximation" of Helmberger et al. [1996b]. Another new method to compute more accurate synthetics for such extreme models was introduced by Wen and Helmberger [1998b]. In this approach, the interaction of $S K S$ and $S K P_{c} S$ with fine-scale $\mathrm{CMB}$ structure near the $S K S$ core exit point is estimated using a finite difference technique, while the propagation of $S K S$ and $S P_{d} K S$ through the core and mantle is treated analytically. A comparison of the "local dipping approximation" against the more exact solution is also made in Figure 6. The synthetics in Figure 6 (right) are computed for a dome that is $80 \mathrm{~km}$ high, $200 \mathrm{~km}$ wide, in which the $P$ and $S$ velocity is reduced by $10 \%$. The dome is positioned with respect to the $S K S$ core exit point to maximize the amplitude of the reflection from the upper boundary of the dome. Internal multiples within the dome while notable are not strong if the $S$ velocity reduction is $<10 \%$, or if the height of the dome is $<20 \mathrm{~km}$ (Figure 7). Synthetics for domes with a height of $40 \mathrm{~km}$ and with $P$ and $S$ velocity reductions of $10 \%$ and $30 \%$, respectively, provide a good match to the Iceland profile, capturing most of the strong interference near $111^{\circ}$. Only the average structure is sufficient for modeling these waveforms. The shape of the dome and the velocity gradient at its top affect the waveforms only marginally [Wen and Helmberger, 1998b].

The models are not only nonunique in terms of trade-offs between structural shape and seismic parameters but also in terms of the position of the ULVZ dome with respect to $S K S$ core exit points (Figure 8). If we place the dome such that the $P$ wave traveling upward within the dome is reflected back downward at the upper boundary of the dome and reflected backup at the core near critical angle $S$, we can generate a strong and delayed $S K P_{d} S$ as displayed on the right. The amplitude of this converted $P$-to- $S$ phase is large only over a few degrees as discussed by Helmberger et al. [1996a], and the geometry becomes extremely important. Small lateral shifts of the dome alter the amplitude of this phase and produce rapid changes in the $S K S-S K P_{d} S$ interference pattern. For example, the recording at KBS near $109^{\circ}$ in Figure 7 is obtained from a distinctly different path than those traveling to KEV and KRK (shown in Plate 3) and can be fit by synthetics for the 20D model and by synthetics for the 40D model which invokes a dome that is shifted slightly to the left (Figure $8 \mathrm{c}$ ). Obviously, without a dense epicentral distance sampling of the $S K S-S K P_{d} S$ we cannot constrain the shape and position of ULVZ domes completely, nor do present-day tomographic models help us to discriminate between viable models at this small scale.

\subsection{Modeling the African Waveform Data}

A broad low shear velocity anomaly is located in D" beneath the eastern Atlantic and Africa (Plate 4, top) which is far more anomalous than the shear velocity structure beneath Iceland. However, station AAE appears to be near the northern edge. We would expect an Iceland-type geometry with the $S K S$ points situated on the limb of the structure and $S K S$ bifurcation waveforms to sample more of the slow velocity. In fact, most AAE waveforms can be modeled with synthetics taken from Figures $\mathbf{8 b - 8 d}$. For these events, $S K S$ emerges to the right 


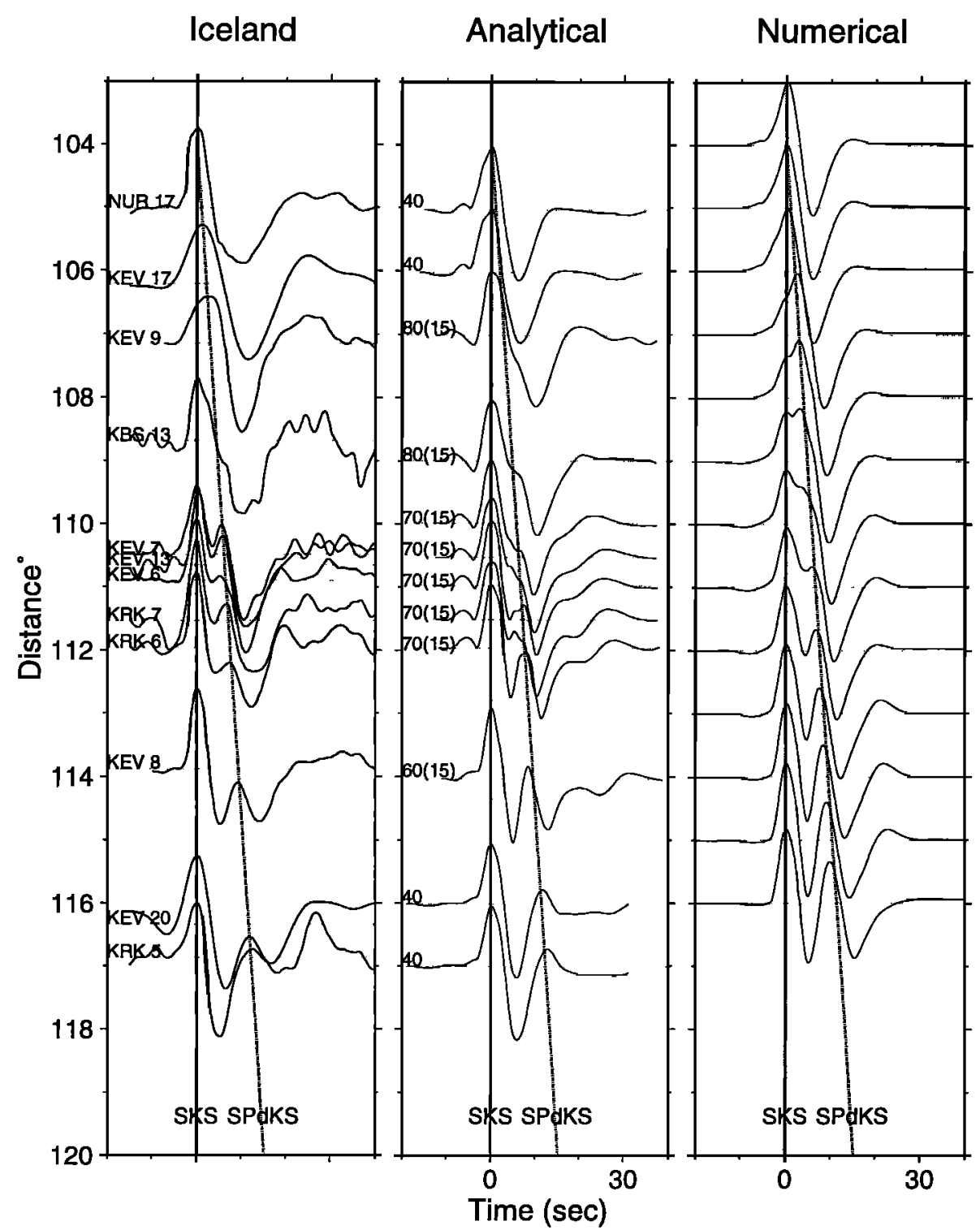

Figure 6. Comparison of (left) the Iceland observations against synthetics produced by (middle) an analytical approach and (right) those generated by the hybrid method (dome). The numbers above the synthetics indicates the ULVZ layer thickness relative to the $S K S$ path with the numbers in parentheses indicating the percentage jump in $\alpha_{3}$. The layer velocities and dome velocities are $10 \%$ lower than PREM both in $P$ and $S$ with the same density. The dome height is $80 \mathrm{~km}$ and is situated relative to $S K S$ to maximize the diffraction amplitude.

of the structure. A comparison of the AAE observations against these synthetics (Figure 8c) is displayed in Figure 9, except for the two records denoted by asterisks, selected from slightly different geometries indicated in Figure 8. Waveform complexities such as a small shoulder in AAE 14 and perhaps the high-amplitude $S K P_{d} S$ pulse in AAE 9 are likely due to 3-D structure. Although the comparison between data and synthetics is not perfect, the 2-D synthetics do explain the very strong secondary arrival near $111^{\circ}$ much better than synthetics computed for models with flat-layered structures.

The waveform corresponding to the southernmost path to AAE, denoted by the black segment in Plate 4 is not as anomalous, and neither are many of the Tanzania array waveforms. This could mean that the ULVZ has pinched out or the geometry here is less favorable to $S K P_{d} S$. It would appear that the $S K S$ exit points are near the maximum slowness, a situation not unlike that producing Figure 8a. For comparison, we added column (d) (Figure 10) containing our best fitting mixed 1-D layered model. The path geometry appears to be in agreement with most of the observations (Figure 10 ) where the $S K P_{c} S$ interference occurs at relatively larger distance than at AAE. These 2-D synthetics were generated from Figures $8 \mathrm{a}$ and $8 \mathrm{~d}$, with a time history adjusted to roughly match the GOMA observation assumed to be $\left(S K S-S K P_{d} S\right)$ interference free. This is relatively simple in the Mix 1-D model since the synthetics reduce essentially to a delta function for distances less than $107^{\circ}$. The 2-D structures with large seismic parameter drops remain somewhat complex at all ranges because of internal multiples, especially in Syn2D2. Figure 10c was included to show the expected behavior for the same dome positions used in modeling the AAE data set but with no long-period WWSSN filter. These waveforms (Syn2D2) do not fit the observations 
very well, especially at the shorter distances. The Syn2D1 synthetics fit the data quite well except at a few stations (SING and PUGE) which prefer a weak $S K P_{\alpha} S$ such as displayed in column Mix 1-D. The broadness of some of the southernmost paths, such as RUNG and MITU, is quite pronounced in agreement with Syn2D1 synthetics. Allowing the geometry to vary slightly would obviously aid in the modeling process; that is, the observations at KIBE look like the average of Syn2D1 and Syn2D2. In short, it appears that the array data are sampling some complex structure on the northern edge of a strong anomaly, which is delaying the development of $S K P_{d} S$. Another possibility is that the ULVZ is fading away into a LVZ such as modeled on the right. Either interpretation yields a picture with rapidly varying CMB structure beneath the northern edge of Grand's [1994] anomalous D" structure. Thus it appears that the African structure is not unlike that occurring beneath the mid-Pacific, essentially a widespread low-velocity zone with pockets of ULVZs beneath some regions.

\section{Discussion}

It appears that an ULVZ exists under a portion of the ALVZ and may be associated with the upwelling process. The ALVZ can be seen in the upper panel of Plate 4 as a low shear velocity structure that extends from the $\mathrm{CMB}$ into the upper mantle, bracketed by $S K S$ and $S K K S$. A much clearer expression of the ALVZ extending into the upper mantle is shown by Ritsema et al. [1999]. However, there appears to be some horizontal offsets along this path. This may indicate a change in the style of convection caused by the expected increase in viscosity at these depths or chemistry [Kellogg et al., 1999]. At shallower depths, receiver function analysis at the Tanzania array also suggest that shear velocities in the transition zone, the structure between the 410 and $660 \mathrm{~km}$ boundaries, are anomalously low [Gurrola et al., 1999]. They suggest lateral changes in the depths to these boundaries and conclude that the transition zone is $\sim 25 \mathrm{~km}$ thinner than the global average of $250 \mathrm{~km}$. A similar result has been reported earlier for the transition zone beneath Iceland [Shen et al., 1996]. The $P$ wave tomographic model by Bijwaard et al. [1998] also suggests that a continuous low-velocity anomaly extends from the upper mantle beneath Iceland to the CMB. Africa and Iceland have both been classified as regions where volcanism may be related to mantle plumes [e.g., Sleep, 1990]. Thus, perhaps the correlation of mantle plumes with anomalous low-velocity regions at the CMB, as proposed by Williams et al. [1998], has merit. Although the evidence is weaker than below Africa, there seems to be a vertical structure beneath the southern Mid-Atlantic Ridge, i.e., near $55^{\circ}$ in Plate 4 (top).

There is direct evidence for an LVZ or perhaps an ULVZ beneath the north Mid-Atlantic as discussed earlier, i.e., path from Sandwich Island to VAL in Plate 2. Thus there appears to be some relationship between the downwelling beneath the Americas and the upwelling to the east. If the fast velocities is indicative of heavy material (cold), as suggested by Sidorin et al. [1999], it may push the thermal boundary layer away from the Americas toward Africa causing it to thicken, which could be the anomalous layer $\left(\mathrm{D}^{\prime \prime}\right)$ near the CMB beneath the ALVZ in Plate 1.

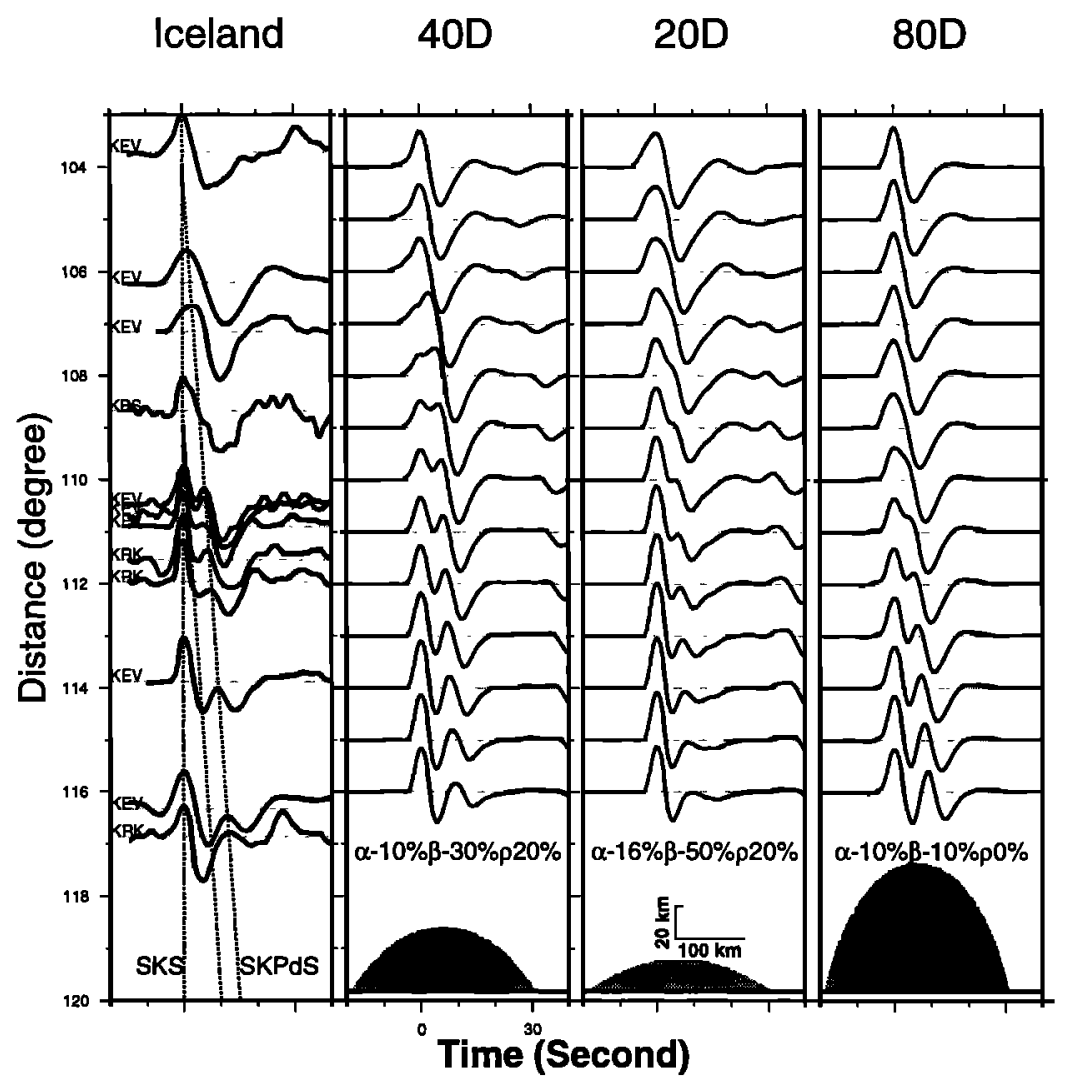

Figure 7. Anomalous observations of South American events recorded at KEV and KRK along with three columns of synthetics. The observations are aligned on $S K S$ with a line indicating the diffraction $S K P_{d} S$. The dome heights are 80,40 , and $20 \mathrm{~km}$ with reductions in velocity as indicated. 

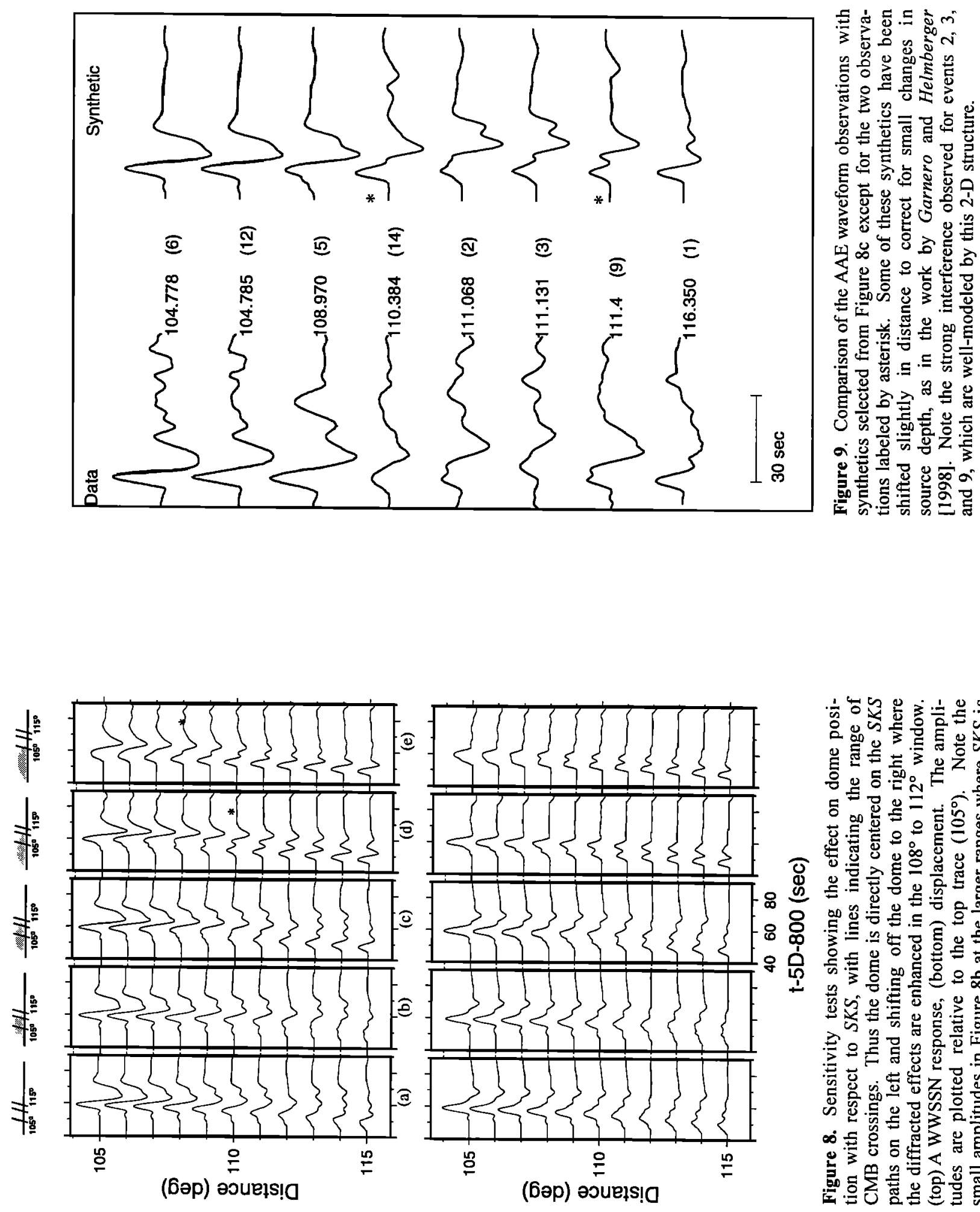

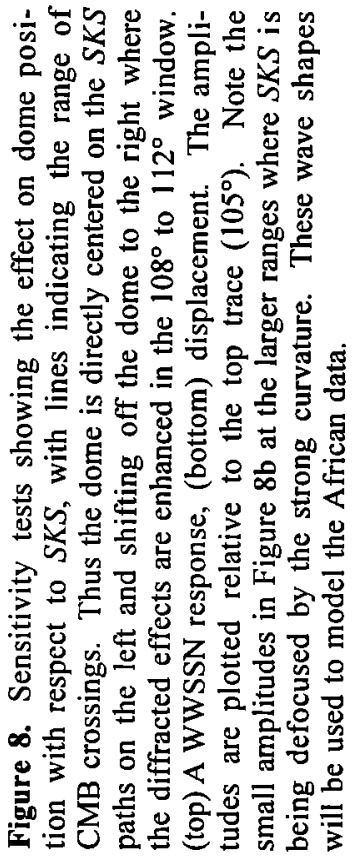




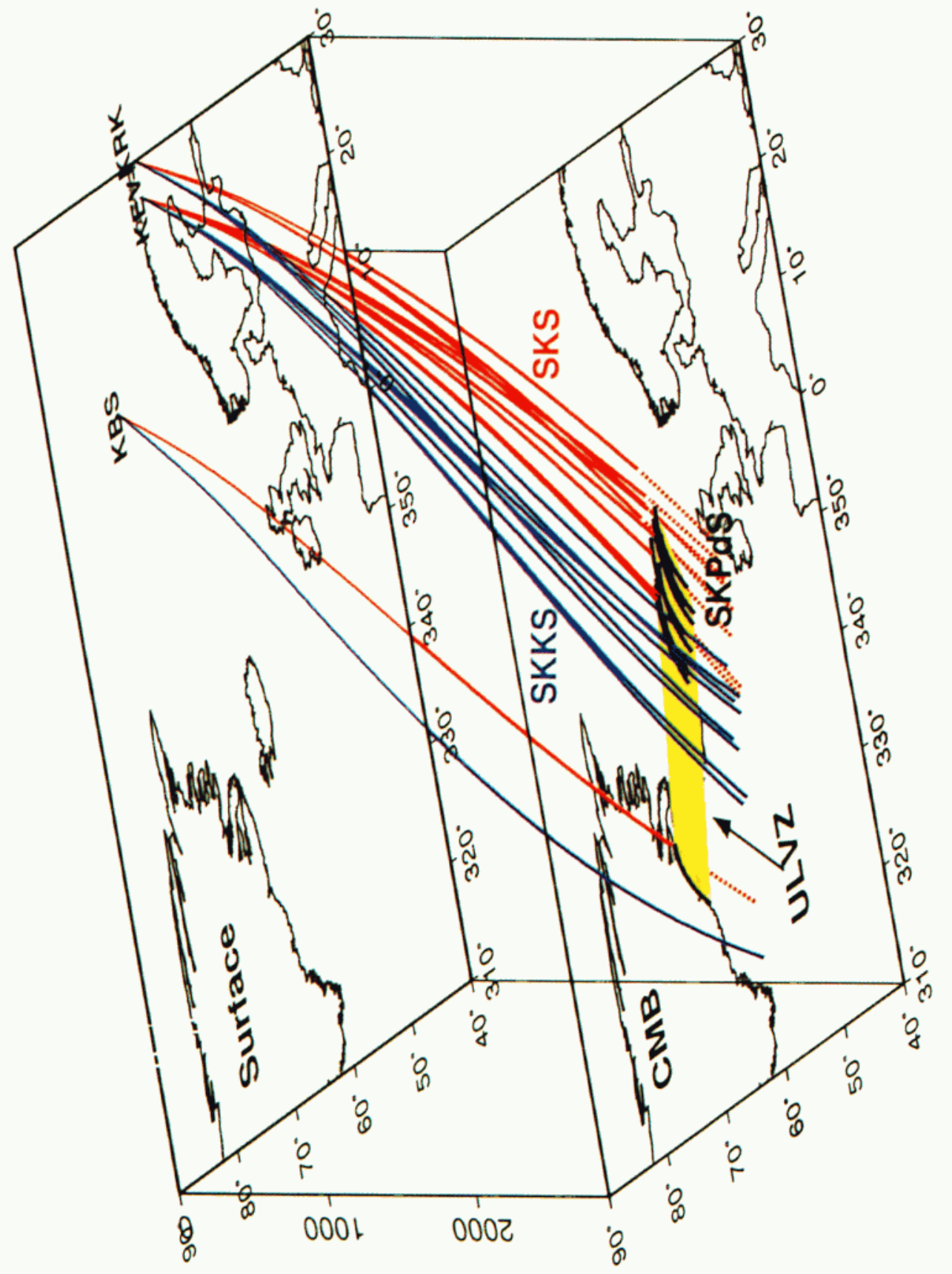

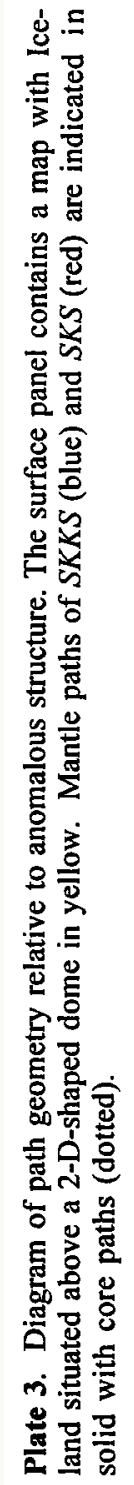




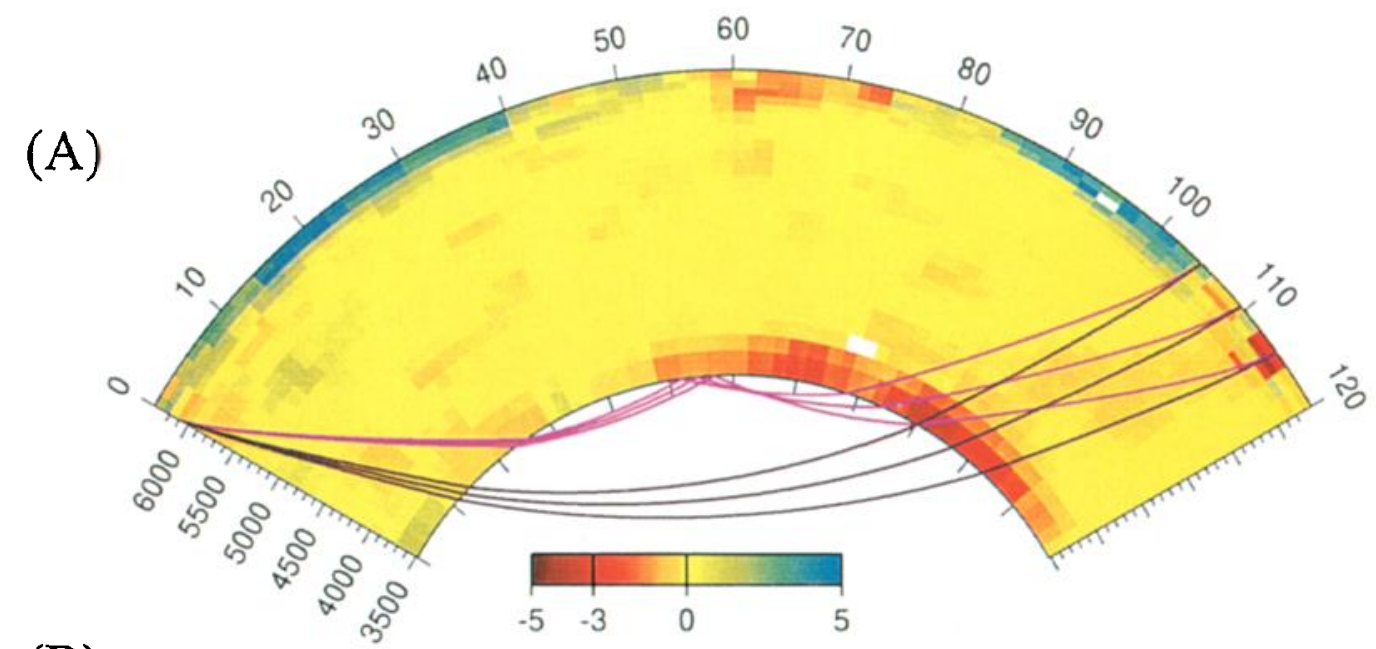

(B)

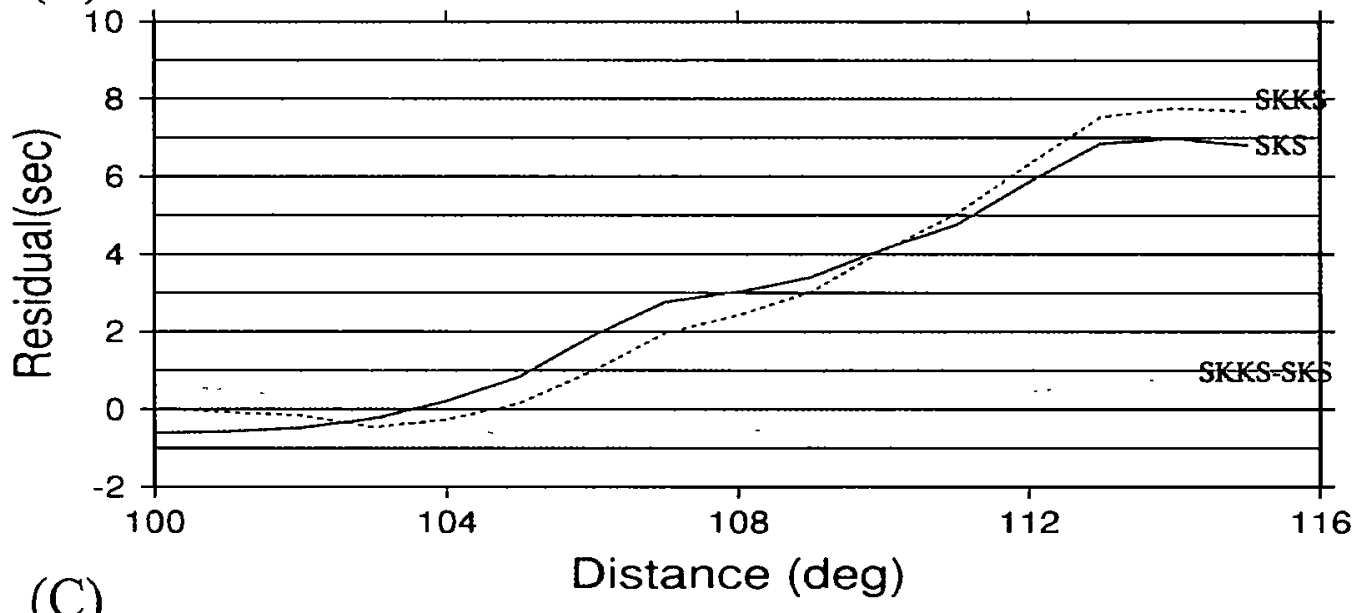

(C)

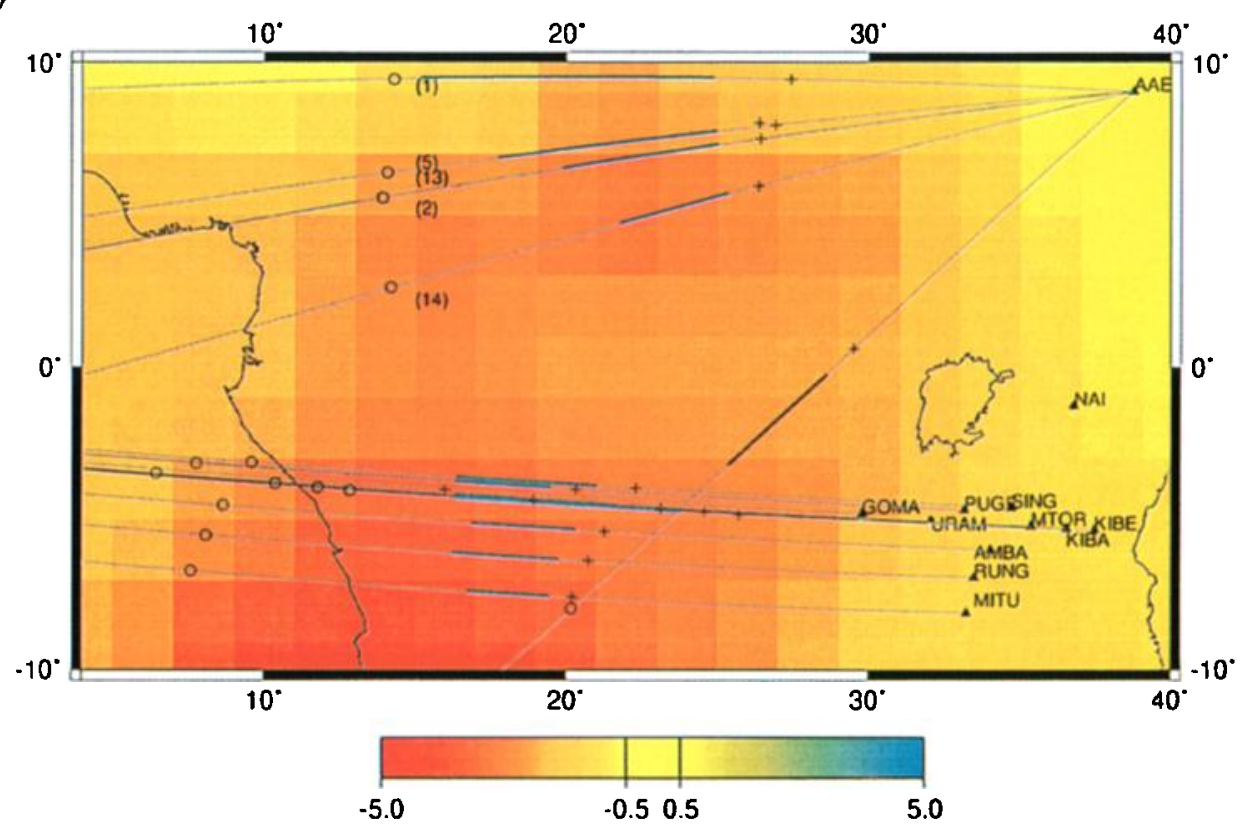

Plate 4. (top) A 2-D section of Grand's tomography model with $S K K S$ (red) and $S K S$ (brown) geometrical paths connecting the South American event to TAN. (middle) Predicted times relative to PREM, $S K S$ (solid) with $S K K S$ (dashed). Note that the differential times (dotted) are nearly zero as observed. (bottom) A detailed map of the CMB showing the piercing points, $S K S$ (crosses) and $S K K S$ (circles) along with $P$ diffraction segments. Also note that the TAN samples of $S K S$ are already well into the slow structure relative to the geometry for AAE. 


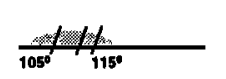

(a)Data

(b)Syn2D1

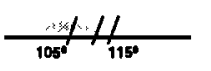

(c)Syn2D2

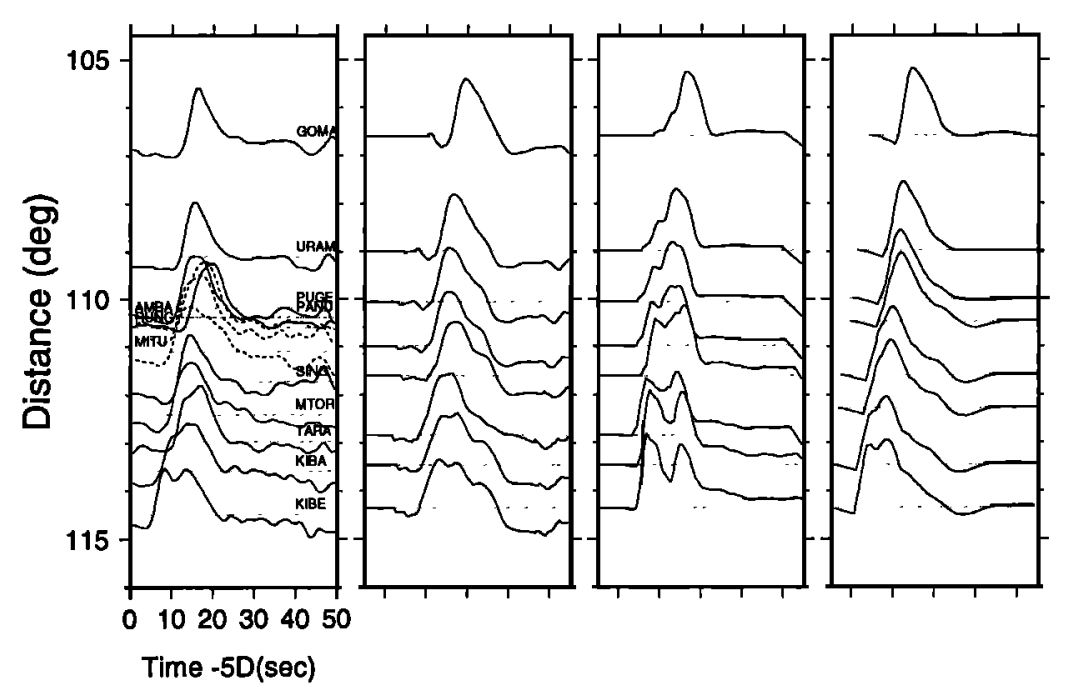

Figure 10. (a) Comparison of TAN observations with synthetics assuming a dome structure and a mixed path. The (b) Syn2D1 and (c) Syn2D2 plots contain the Green's functions given in Figures 8a and 8d. (d) The synthetic Mix 1D contains the layered approximation with PREM on the source end, and a 5\% drop in a layer 30 $\mathrm{km}$ thick beneath the array (see Figure 5). The dotted traces correspond to the southernmost paths as displayed in Plate 4.

Another explanation is that the $D^{\prime \prime}$ structure beneath ALVZ is simply a manifestation of a small amount of melt. As suggested by Knittle [1998], we might expect some chemical differentiation assuming a hot lower mantle [Holland and Ahrens, 1997]. Some melt would move upward fueling the upwelling directly and some would move downward forming a heavy slow $\mathrm{D}^{\prime \prime}$, providing the CMB density anomaly proposed by Ishii and Tromp [1999]. In this context, the ULVZs would just be a local concentration of particularly strong melt below a major upwelling.

In conclusion, we have reviewed existing $S K S$ bifurcation waveform data in comparison with observations sampling beneath Iceland and Pacific with new data from Africa. To model the extreme delays and strengths of $S K P_{d} S$ relative to $S K S$ in some observations requires ULVZs containing shortwavelength structures on the CMB. Thus we have examined the ray paths through the Grand's [1994] tomography model in detail for the simplest situation (Iceland) with the most complex (Africa). Velocity drops in $S$ of up to $30 \%$ and curvature of interfaces of $40 \mathrm{~km}$ over $300 \mathrm{~km}$ laterally proved effective in modeling efforts in both situations. However, these synthetics are 2-D and the structure is obviously 3-D. Thus, to resolve these detailed features of ULVZs in relationship to surrounding structure will require very dense station coverage of the type proposed in the U.S. array experiment along with 3-D synthetics.

Acknowledgment. This research has been supported by National Science Foundation grant EAR97-2508. We thank Michael Gumis for his helpful suggestions and the thoughtful comments by the referees, Rob van der Hilst, Barbara Romanowicz, and John Castle. Contribution 8633 of the Division of Geological and Planetary Sciences, California Institute of Technology.

\section{References}

Bijwaard, H., W. Spakman, and R. Engdahl, Closing the gap between regional and global travel time tomography, J. Geophys. Res., 103, 30,055-30,078, 1998.

Breger, L., and B. Romanowicz, Three-dimensional structure at the base of the mantle beneath the central Pacific, Science, 282, 718-720, 1998.

Chase, C. G., and D. R. Sprowl, The modern geoid and ancient plate boundaries, Earth Planet. Sci. Lett., 62, 314-320, 1983.

Crough, S. T., and D. M. Jurdy, Subducted lithosphere, hot spots, and the geoid, Earth Planet. Sci. Lett., 48, 15-22, 1980.

Davies, G. F., Thermal histories of convective earth models and constraints on radiogenic heat production in the earth, J. Geophys. Res., 85, 2517-2530, 1980.

Dziewonski, A. M., and D. L. Anderson, Preliminary reference Earth model (PREM), Phys. Earth Planet. Inter., 25, 297-356, 1981.

Engebretson, D. C., K. P. Kelley, H. J. Cashman, and M. A. Richards, 180 million years of subduction, GSA Today, 2, 93-100, 1992.

Garnero, E. J., and D. V. Helmberger, On seismic resolution of lateral heterogeneity in the Earth's outermost core, Phys. Earth Planet. Inter., 88, 117-130, 1995.

Garnero, E. J., and D. V. Helmberger, Seismic detection of a thin laterally varying boundary layer at the base of the mantle beneath the central-Pacific, Geophys. Res. Lett., 23, 977-980, 1996.

Garnero, E. J., and D. V. Helmberger, Further structural constraints and uncertainties of a thin laterally ultralow-velocity layer at the base of the mantle, J. Geophys. Res., 103, 12,495-12,509, 1998.

Garnero, E. J., S. P. Grand, and D. V. Helmberger, Low $P$-wave velocity at the base of the mantle, Geophys. Res. Lett., 20, 1843-1846, 1993.

Grand, S. P., Mantle shear structure beneath the Americas and surrounding oceans, J. Geophys. Res., 99, 11,591-11,621, 1994.

Grand, S. P., R. D. van der Hilst, and S. Widiyantoro, Global seismic tomography: A snapshot of convection in the Earth, GSA Today, 7, 1-7, 1997.

Gurrola, H., T. J. Owens, A. A. Nyblade, and C. A. Langston, Three Dimensional structure of the mantle transition zone beneath the Tanzanian Craton and surrounding Mobile Belts, East Africa, paper presented at IRIS 11 th Annual Workshop, Inc. Res. Inst. for Seismol., Yosemite National Park, Calif., 1999. 
Hager, B. H., R. W. Clayton, M. A. Richards, R. P. Comer, and A. M. Dziewonski, Lower mantle heterogeneity, dynamic topography and the geoid, Nature, 3/3, 541-545, 1985.

Helmberger, D. V., Theory and application of synthetic seismograms, in Earthquakes: Observation, Theory, and Interpretation, vol. 37, Italian Physical Society (Enrico Fermi), edited by H. Kanamori and E. Boschi, pp. 174-217, North-Holland, New York, 1983.

Helmberger, D. V., E. J. Garnero, and X. Ding, Modeling two-dımensional structure at the core-mantle boundary, J. Geophys. Res., 101, $13,963-13,972,1996 a$.

Helmberger, D. V., L.-S. Zhao, and E. J Garnero, Construction of synthetics for 2D structures; core phases, in Selsmic Modeling of the Earth Structure, edited by E. Boschi, G. Ekstrom, and A. Morelli, pp. 183-222, North-Holland, New York, 1996b.

Helmberger, D. V., L. Wen, and X. Ding, Seismic evidence that the source of the Iceland hot spot lies at the core-mantle boundary, $\mathrm{Na}$ ture, 396, 251-255, 1998.

Holland, K. G., and T. J. Ahrens, Melting of (Mg, Fe $)_{2} \mathrm{SiO}_{4}$ at the coremantle boundary of the Earth, Science, 275, 1623-1625, 1997.

Hong, T.-L., and D. V. Helmberger, Generalized ray theory for dipping structure, Bull. Setsmol. Soc. Am., 67, 995-1008, 1977.

Ishii, M., and J. Tromp, Normal-mode and free-air gravity constraints on lateral variations in velocity and density of Earth's mantle, Science, 285, 1231-1234, 1999.

Kellogg, L., B. H. Hager, and R. D. Van der Hilst, Compositional stratification in the deep mantle, Science, 283, 1881-1884, 1999.

Kind, R., and G. Muller, Computations of $S V$ waves in realistic Earth models, J. Geophys., 4I, 149-172, 1975.

Knittle, E., The solid/liquid partitioning of major and radiogenic elements at lower mantle pressures: Implications for the core-mantle boundary region, in The Core-Mantle Boundary Region, Geodyn. Ser., vol. 28 edited by M. Gurnis et al., pp. 119-130, AGU, Washington, D.C, 1998.

Lay, T., E. J. Garnero, Q. Williams, B. Romanowicz, L. Kellogg, and M E. Wysession, Seismic wave anisotropy in the D" region and its implications, in The Core-Mantle Boundary Regıon, Geodyn. Ser., vol 28 , edited by M. Gurnis et al., pp. 299-318, AGU, Washington, D.C., 1998.

Li, X. D., and B. Romanowicz, Global mantle shear velocity model developed using nonlinear asymptotic coupling theory, $J$ Geophys. Res., $101,22,245-22,272,1996$.

Masters, G., S. Johnson, G. Laske, and H. Bolton, A shear-velocity model of the mantle, Philos. Trans. Ry. Soc. London, 354, 1385-1410, 1996.

Mori, J., and D. V. Helmberger, Localized boundary layer below the mid-Pacific velocity anomaly identified from a $P c P$ precursor, $J$. Geophys. Res., 100, 20,359-20,365, 1995.

Ni, S., X. Ding, and D. V. Helmberger, Constructing synthetics from deep Earth tomographic models, Geophys J. Int., 140, 71-82, 2000.

Nyblade, A. A., C. Birt, C. A. Langston, T. J. Owens, and R. Last, Seismic experiment reveals rifting of craton in Tanzania, Eos Trans. $A G U, 77,517,521,1996$.

Revenaugh, J., and R. Meyer, Seismic evidence of partial melt within a possibly ubiquitous low-velocity layer at the base of the mantle, Science, 277, 670-673, 1997

Ritsema, J., A. A. Nyblade, T. J. Owens, C. A. Langston, and J. C. VanDecar, Upper mantle seismic velocity structure beneath Tanzania, East Africa: Implications for the stability of cratonic lithosphere, $J$. Geophys. Res., 103, 21,201-21,213, 1998a.

Ritsema, J., S. Ni, D. V. Helmberger, and H. P. Crotwell, Evidence for strong shear velocity reductions and velocity gradients in the lower mantle beneath Africa, Geophys. Res. Lett., 25, 4245-4248, 1998 b.

Ritsema, J., H. van Heijst, and J. Woodhouse, Complex shear wave velocity structure imaged beneath Africa and Iceland, Science, 286, 1925-1928, 1999.

Ritzwoller, M. H., and E. M. Lavely, Three-dimensional seismic models of the Earth's mantle, Rev. Geophys., 33, 1-66, 1995.

Shen, Y., S. C. Soloman, I. Bjarnason, and G. M. Purdy, Hot mantle transition zone beneath Iceland and the adjacent Mid-Atlantic Ridge inferred from $P$ to $S$ conversions at the 410 and $660 \mathrm{~km}$ discontinuities, Geophys. Res. Lett., 23, 3527-3530, 1996.

Sidorin, I., M. Gurnis, and D. V. Helmberger, Evidence for an ubiquitous seismic discontinuity at the base of the mantle, Science, 286, 1326$1331,1999$.

Sleep, N. H., Hotspots and mantle plumes: Some phenomenology, $J$. Geophys. Res., 95, 6715-6736, 1990.

Su, W.-J., R. L. Woodward, and A. M. Dziewonsk1, Degree 12 model of shear velocity heterogeneity in the mantle, J. Geophys. Res., 99, 6945-6980, 1994.

Thompson, P. F , and P. J. Tackley, Generation of mega-plumes from the core-mantle boundary in a compressible mantle with temperaturedependent viscosity, Geophys. Res. Lett., 25, 1999-2002, 1998.

Wen, L., and D. V. Helmberger, Ultra-low velocity zones near the coremantle boundary from broadband PKP precursors, Science, 279, 1701-1703, 1998a.

Wen, L., and D. V. Helmberger, A two-dimensional $P$-SV hybrid method and its application to modeling localized structures near the coremantle boundary, J. Geophys. Res., 103, 17,901-17,918, 1998b.

Williams, Q., and E. J. Garnero, Seismic evidence for partial melt at the base of Earth's mantle, Science, 273, 1528-1530, 1996

Williams, Q., J. Revenaugh, and E. J. Garnero, A correlation between the hot spot distribution and ultra-low basal velocities in the mantle, Science, 281, 549-564, 1998.

Zhang, S., and D. A. Yuen, Various influences on plumes and dynamics in time-dependent, compressible mantle convection in 3D spherical shell, Phys. Earth Planet. Inter., 94, 242-267, 1997.

D. Helmberger, S. Ni, and J. Ritsema, Seismological Laboratory, 25221, California Institute of Technology, Pasadena, CA 91125. (helm@gps.caltech.edu)

L. Wen, Department of Terrestrial Magnetism, Carnegie Institution of Washington, 5241 Broad Branch Road, N.W., Washington, DC 20015.

(Received July 12, 1999; revised March 27, 2000;

accepted April 13, 2000.) 